Brazilian Journal

of Chemical

ISSN 0104-6632

Printed in Brazil

Engineering

www.scielo.br/bjce

Vol. 35, No. 02, pp. 669 - 678, April - June, 2018

dx.doi.org/10.1590/0104-6632.20180352s20160703

\title{
HYDROTALCITE-IMPREGNATED COPPER AND CHROMIUM-DOPED COPPER AS NOVEL AND EFFICIENT CATALYSTS FOR VAPOR-PHASE HYDROGENATION OF FURFURAL: EFFECT OF CLAY PRETREATMENT
}

\author{
Mohammad Ghashghaee ${ }^{1,2 *}$, Samira Shirvani ${ }^{1,2}$, Vahid Farzaneh ${ }^{1,2}$ and \\ Samahe Sadjadi ${ }^{2,3}$ \\ ${ }^{1}$ Faculty of Petrochemicals, Iran Polymer and Petrochemical Institute, P.O. Box \\ 14975-112, Tehran, Iran \\ ${ }^{2}$ Biomass Conversion Science and Technology (BCST) Division, Iran Polymer and \\ Petrochemical Institute, P.O. Box 14975-115, Tehran, Iran \\ ${ }^{3}$ Gas Conversion Department, Faculty of Petrochemicals, Iran Polymer and \\ Petrochemical Institute, P.O. Box 14975-112, Tehran, Iran
}

(Submitted: December 18, 2016; Revised: March 20, 2017; Accepted: March 24, 2017)

\begin{abstract}
A series of novel catalysts based on immobilization of copper and chromium-doped copper on calcined and uncalcined hydrotalcite support have been developed and used for promoting vapor-phase hydrogenation of furfural. The results indicated that a pre-calcination of the support has a negative role in changing the structural features and catalytic activity of the final catalysts. Moreover, the presence of the $\mathrm{Cr}$ promoter can improve the catalyst performance. The best performance (furfuryl alcohol selectivity of $94 \%$ and furfural conversion of $89 \%$ ) was obtained over the Cr-doped copper catalyst supported on as-synthesized hydrotalcite material.
\end{abstract}

Keywords: Hydrotalcite, Furfuryl alcohol, Hydrogenation, Copper catalysts, Biomonomers.

\section{INTRODUCTION}

Furfural (FF) is an important biomass-derived starting material and chemical building block (Taylor et al., 2016; Li et al., 2016c) which can be easily obtained through fast pyrolysis of biomass or dehydration of xylose (Sulmonetti et al., 2016). The increasing attention to this important platform stems unequivocally from its potential (Marcotullio, 2011, 2013; De Jong and Marcotullio, 2010) to convert it to numerous chemicals and fuels, including furfurylamine, maleic acid, linear alkanes, furoic acid, 2-methyl tetrahydrofuran, 2-methylfuran, furan, cyclopentanone, tetrahydrofurfuryl alcohol, 1,5-pentanediol, and furfuryl alcohol (Yan et al., 2013; Zhu et al., 2014; Yuan et al., 2015; Yan and Chen, 2014; Sulmonetti et al., 2016; Halilu et al., 2016; Vargas-Hernández et al., 2014; Jiménez-Gómez et al., 2016; Manikandan et al., 2016a; Yan et al., 2014). Among various conversions, catalytic hydrogenation of FF to furfuryl alcohol (FFA)

* Corresponding author. Tel.: +98 21 48662481; fax: +98 21 44787032. E-mail address: m.ghashghaee@ippi.ac.ir 
has earned a noticeable interest because of its utility for synthesis of value-added products such as farm chemicals, adhesives, furan fiber-reinforced plastics, foundry resins, thermostatic resins, liquid resins, lubricants, dispersing agents, ascorbic acid and lysine (Xu et al., 2015; Nagaraja et al., 2007; Yuan et al., 2015; Taylor et al., 2016).

Catalytic conversion of FF to FFA can be achieved either in the gas phase (Nagaraja et al., 2007; Li et al., 2015; Yan and Chen, 2013; Jiménez-Gómez et al., 2016) or the liquid phase (Yuan et al., 2015; Sharma et al., 2013; Villaverde et al., 2015; Li et al., 2016b; O'Driscoll et al., 2016; Li et al., 2016a). However, the gas-phase process is favored as it can be run under milder reaction conditions (Vargas-Hernández et al., 2014). In industry, the gas-phase hydrogenation is carried out at pressures up to 30 bar and temperatures ranging between 130 and $200{ }^{\circ} \mathrm{C}$ under copper chromite catalysis (Kijeński et al., 2002). Although the catalytic activity of copper chromite is acceptable, its moderate selectivity still remains a challenge. In this regard, many attempts have been devoted to developing alternative catalysts such as $\mathrm{Cu}, \mathrm{Ni}, \mathrm{Pd}, \mathrm{Co}, \mathrm{Ru}$, Ir, and Pt catalysts supported on a relatively inert material such as silica and alumina (Halilu et al., 2016; Nagaraja et al., 2011; Nakagawa et al., 2014; Lesiak et al., 2014; An et al., 2013; Aldosari et al., 2016). Among these catalysts, $\mathrm{Cu}-\mathrm{MgO}$ has been subjected to many studies because of its low cost, high activity and selectivity to FFA (Vargas-Hernández et al., 2014; Nagaraja et al., 2007; Nagaraja et al., 2003; Cui et al., 2015; Estrup, 2015; Liu et al., 2015; Nagaraja et al., 2011; Sadjadi et al., 2017; Ghashghaee et al., 2017; Shirvani et al., 2017; Farzaneh et al., 2017).

Layered double hydroxides (LDHs), also referred to as hydrotalcite-like compounds (Xu et al., 2011), are a class of clays with the general formula of $\left[\mathrm{M}^{2+}{ }_{1-x} \mathrm{M}^{3+}{ }_{x}\right.$ $\left.(\mathrm{OH})_{2}\right]\left[\mathrm{A}^{n-}\right]_{x / n} \cdot m \mathrm{H}_{2} \mathrm{O}$, in which $\mathrm{M}^{2+}$ and $\mathrm{M}^{3+}$ are divalent and trivalent metal cations, and $\mathrm{A}^{n-}$ is a counter anion (Liu et al., 2016). Although LDHs have been widely used in catalysis (Thirumalaiswamy et al., 2015; Basini et al., 2002; Wei et al., 2010; Baskaran et al., 2015; Thangaraj et al., 2016; Wang et al., 2017; Karthikeyan and Karuppuchamy, 2017; Hernández et al., 2017; D'Oca et al., 2017; Eskandari et al., 2017; Santos et al., 2017), there are only a few reports on their utility as the catalyst support for the gas-phase hydroconversion of FF to FFA (Manikandan et al., 2016b; Sangeetha et al., 2009); in none of them copper and chromiumdoped copper species were supported (impregnated) on Mg-Al hydrotalcite. To the best of our knowledge, the effect of a pre-calcination of the hydrotalcite support on the catalytic activity of copper catalysts for the above-mentioned process was not reported in the literature.

Taking into account the outstanding properties of hydrotalcite support and the importance of conversion of $\mathrm{FF}$, in this paper we wish to report the utility of hydrotalcite for supporting copper and chromiumdoped copper species for developing novel catalysts for promoting catalytic hydrogenation of FF to FFA. Moreover, for the first time we study the effect of the pretreatment (pre-calcination) of hydrotalcite on the catalytic activity of the final catalyst to highlight the importance of the hydrotalcite pretreatment on its performance as a support.

\section{EXPERIMENTAL}

\section{Materials}

The chemicals used for the synthesis of catalysts included $\mathrm{Mg}\left(\mathrm{NO}_{3}\right)_{2} \cdot 6 \mathrm{H}_{2} \mathrm{O}$ (ACS reagent, 99\%), $\mathrm{Cu}\left(\mathrm{NO}_{3}\right)_{2} \cdot 3 \mathrm{H}_{2} \mathrm{O}(99.5 \%), \mathrm{Na}_{2} \mathrm{CO}_{3}(99.9 \%), \mathrm{NaOH}$ (ACS reagent, 98\%), $\mathrm{Al}\left(\mathrm{NO}_{3}\right)_{3} \cdot 6 \mathrm{H}_{2} \mathrm{O}(99 \%)$ and $\mathrm{Cr}\left(\mathrm{NO}_{3}\right)_{3} \cdot 9 \mathrm{H}_{2} \mathrm{O}(97 \%)$. All were provided from Merck except the latter that was purchased from Scharlau. The starting materials were used as received without any further purification. The materials employed in the catalytic runs included FF (98.90\%, Merck) and high purity hydrogen $(99.99 \%)$ and nitrogen $(99.99 \%)$.

\section{Catalyst preparation}

\section{Preparation of support}

A conventional co-precipitation method was used for the synthesis of hydrotalcite (abbreviated as HT) (Li et al., 2006). Briefly, to a stirred mixture of $1 \mathrm{~mol}$ of $\mathrm{Mg}\left(\mathrm{NO}_{3}\right)_{2} \cdot 6 \mathrm{H}_{2} \mathrm{O}$ and $0.5 \mathrm{~mol}$ of $\mathrm{Al}\left(\mathrm{NO}_{3}\right)_{3} \cdot 9 \mathrm{H}_{2} \mathrm{O}$ (with an $\mathrm{Mg} / \mathrm{Al}$ molar ratio of 2) in $700 \mathrm{~mL}$ of deionized water a solution of $3.5 \mathrm{~mol}$ of $\mathrm{NaOH}$ and $0.943 \mathrm{~mol}$ of $\mathrm{Na}_{2} \mathrm{CO}_{3}$ was added dropwise to adjust the final $\mathrm{pH}$ to 13 . Subsequently, the mixture was heated at $65^{\circ} \mathrm{C}$ for $18 \mathrm{~h}$. The resulting precipitate obtained by vacuum filtration was washed thoroughly with deionized water to reach a neutral $\mathrm{pH}$ and then dried overnight at $130^{\circ} \mathrm{C}$. Half of the solid was further used without calcination and the remaining part was calcined at 550 ${ }^{\circ} \mathrm{C}$ for $5 \mathrm{~h}$ to obtain the final oxide catalyst.

\section{Supporting the catalytic species}

Wet impregnation was used for supporting the copper and copper chromite species on the prepared 
supports. In a typical procedure, the HT support was suspended in deionized water and stirred vigorously. Subsequently, a solution of $\mathrm{Cu}\left(\mathrm{NO}_{3}\right)_{2} \cdot 3 \mathrm{H}_{2} \mathrm{O} 11 \%$ (wt/ wt) in deionized water was added dropwise to the aforementioned suspension. The obtained mixture was then impregnated for $24 \mathrm{~h}$ at ambient temperature. Upon completion of the process, the catalyst was dried in an oven at $150{ }^{\circ} \mathrm{C}$ for $12 \mathrm{~h}$ and afterward calcined at $550{ }^{\circ} \mathrm{C}$ for $5 \mathrm{~h}$. The obtained catalysts were denoted as CHT1 and CHT3 for the calcined and uncalcined supports, respectively. The hydrotalcite-supported chromium-copper catalysts were prepared via the same procedure except that $\mathrm{Cr}\left(\mathrm{NO}_{3}\right)_{3} .9 \mathrm{H}_{2} \mathrm{O} 5.5 \%$ (wt/ wt) was added together with the copper precursor during the impregnation. These two catalysts were named CHT2 and CHT4 as the counterparts of CHT1 and $\mathrm{CHT} 3$, respectively.

\section{Characterization of the catalysts}

The analytical methods employed for the characterization of the synthesized catalysts included SEM, EDX, BET, XRD, and TGA.ATescan instrument, using Au-coated samples with an acceleration voltage of $20 \mathrm{kV}$ was used for taking SEM/EDX images. The measurement of BET surface area was carried out after nitrogen physisorption using a Quantachrome ChemBET 3000 sorption analyzer at $77 \mathrm{~K}$. Degassing of the sample was performed at $120{ }^{\circ} \mathrm{C}$ for $3 \mathrm{~h}$ prior to the BET analysis. Room temperature powder X-ray diffraction patterns were collected using a Siemens D5000. $\mathrm{Cu} \mathrm{K} \alpha$ radiation was used from a sealed tube. Data were collected in the $2 \theta$ range of $30-65^{\circ}$ with a step size of $0.02^{\circ}$ and an exposure time of $2 \mathrm{~s}$ per step. Perkin Elmer Pyris 1 instrument with $10{ }^{\circ} \mathrm{C} / \mathrm{min}$ ramping in nitrogen atmosphere was applied for the thermogravimetric analysis (TGA) and obtaining the derivative thermogravimetric (DTG) curves of the spent catalysts.

\section{Catalytic activity}

The atmospheric vapor-phase conversion of FF over the hydrotalcite-supported catalysts was conducted in a continuous flow tubular reactor inside an electrically heated furnace. In each run, the fixed bed of catalyst pellets $(0.3-1.0 \mathrm{~mm})$ was placed between two plugs of quartz wool. The temperature of the reactor was maintained by two thermocouples and two programmable temperature controllers. Prior to the reaction, the catalyst was reduced in a dilute flow of hydrogen (33 vol.\%) in nitrogen with a total flow rate of $6.4 \mathrm{Lg}^{-1} \mathrm{~h}^{-1}$ at $250{ }^{\circ} \mathrm{C}$ for $3 \mathrm{~h}$. Then, the catalyst bed was cooled down to the reaction temperature in pure hydrogen. Afterwards, FF was injected into the reactor using a motorized syringe pump. The reaction was carried out at the temperature of $180{ }^{\circ} \mathrm{C}$ and WHSV of $1.7 \mathrm{~h}^{-1}$ with a hydrogen-to-feed $\left(\mathrm{H}_{2} / \mathrm{HC}\right)$ volumetric ratio of 10 . The hydrogenation process was followed by collecting the liquid products in an ice trap and analyzing on a gas chromatograph (GC) equipped with a capillary column and a flame ionization detector (FID). The carbon balance was higher than $95 \%$ in all experiments unless otherwise stated. The outlet molar flow rates were accordingly normalized assuming a closed carbon balance for the interpretations. Finally, the performance of the catalyst was estimated using the following definitions:

$$
\text { Conversion }(\%)=\frac{\text { moles of FF consumed }}{\text { moles of FF fed }} \times 100
$$

Selectivity $(\operatorname{mol} \%)=\frac{\text { moles of desired product }}{\text { moles of } \mathrm{FF} \text { consumed }} \times 100$

Yield $(\operatorname{mol} \%)=\frac{\text { moles of desired product }}{\text { moles of FF fed }} \times 100$

where the performance data were reproducible to within $\pm 2 \%$.

\section{RESULTS AND DISCUSSION}

Fig. 1 compares the performance of the four synthesized catalysts in terms of FF conversion, FFA selectivity, and FFA yield for the vapor-phase hydrogenation process. As observed in this figure, the most selective catalyst was CHT3 with FFA selectivities higher than $98 \%$ in the whole range of the hydrogenation process. Although this catalyst showed sustained selectivity during the operation, its FFA yield and FF conversion declined moderately from $92.4 \%$ and $96.4 \%$ respectively to $50.8 \%$ and $51.1 \%$. This trend showed how this catalyst suffered from a gradual deactivation with time. Comparatively, CHT4 proved to have a superior performance relative to other catalysts (see Fig. 1). In addition to its high and sustained selectivity towards FFA (more than 94\%), there appeared only mild variations in its FF conversion and FFA yield levels during the $4 \mathrm{~h}$ experimental run in such a manner that the values of these parameters remained respectively above $89 \%$ and $87 \%$. In contrast, the CHT1 and CHT2 catalysts exhibited poor performances in the vaporphase hydrogenation of FF, particularly in terms of FF 
conversion and FFA yield, which were lower than 3\% on both of the catalysts during the operation. In fact, the non-calcined hydrotalcite-supported catalysts were much more efficient than those on the calcined supports in the FF hydrogenation process. This is an interesting observation, proving that a pre-calcination of the support is not beneficial for the favored reactions. Nevertheless, CHT2 with an about $80 \%$ selectivity towards FFA after $4 \mathrm{~h}$ of operation was more favorable than $\mathrm{CHT} 1$ with an FFA selectivity of $\sim 50 \%$. Moreover, by incorporating $\mathrm{Cr}$ as a promoter, the catalysts behaved more durably under the conditions employed. Therefore, as illustrated in Fig. 1, the best overall performance belonged to CHT4, the non-calcined hydrotalcite-supported chromiumpromoted copper catalyst.
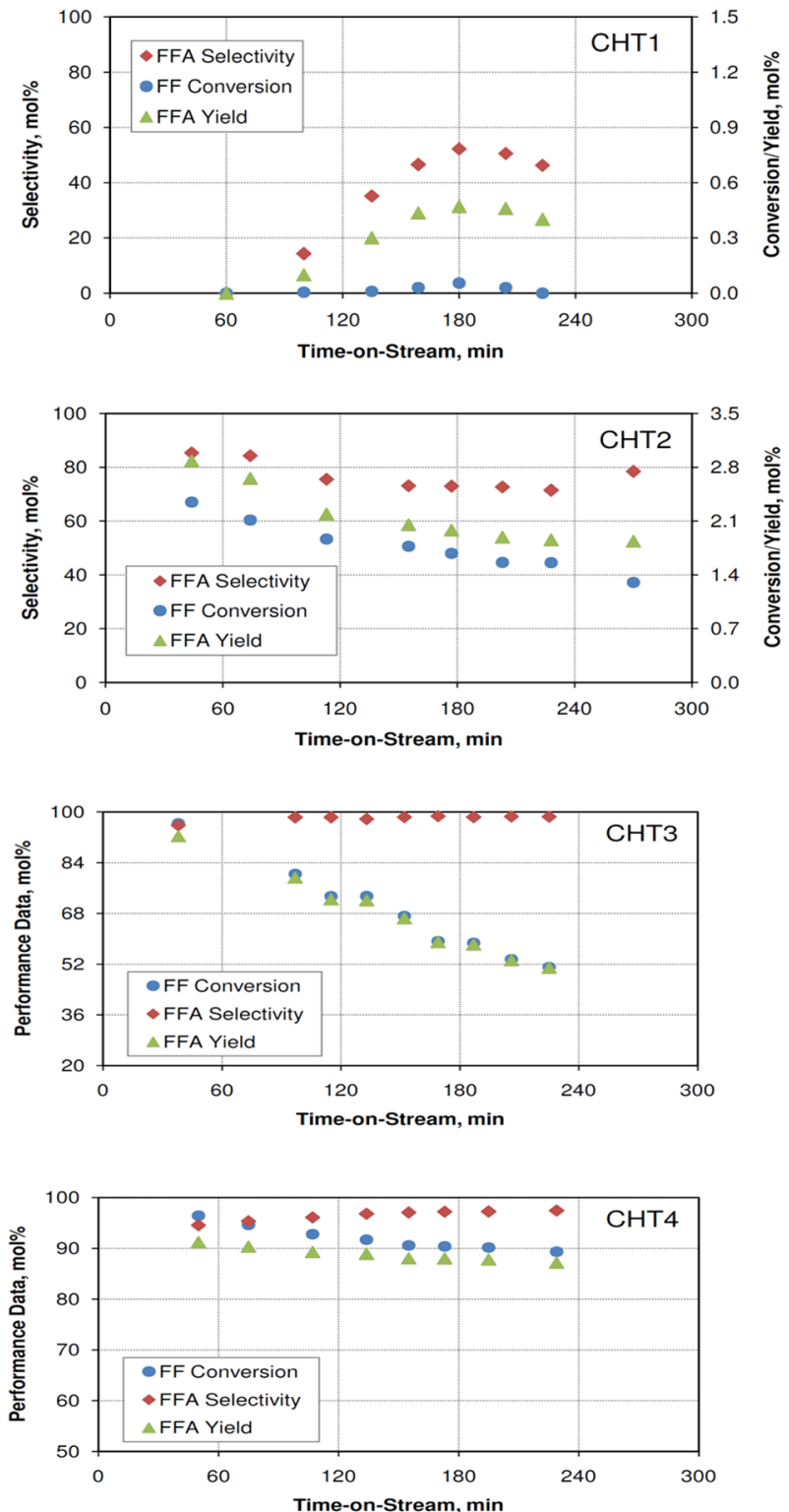

Figure 1. The main performance data for the hydrotalcite-supported copper catalysts in the catalytic conversion of FF to FFA at $180{ }^{\circ} \mathrm{C}, 1 \mathrm{~atm}$, WHSV of $1.7 \mathrm{~h}^{-1}$, and $\mathrm{H}_{2} / \mathrm{HC}$ of 10 .
A schematic diagram of the plausible reactions leading to the observed products is shown in Fig. 2. Moreover, Fig. S1 presents the trends of important byproducts which were produced on the synthesized catalysts during $4 \mathrm{~h}$ of operation. As can be seen, the only byproduct of the hydrogenation process over CHT1 was 5-methylfurfural (MFF), which was produced exactly with a reverse trend against FFA (see Fig. 1). More precisely, at the initial times of catalytic run, the selectivity of the CHT1 catalyst towards MFF was $100 \%$, which then decreased sharply and reached the level of $50 \%$ and stayed almost constant at this plateau until the end of run. The byproducts of the CHT2 catalyst included MFF and 2-acetylfuran (AF). MFF increased gradually with time on CHT2. Although the variety of the byproducts obtained over CHT3 and CHT4 was more pronounced than on CHT1 and CHT2, the selectivities of the byproducts over the two former catalysts were significantly lower (up to $\sim 3 \%$ of each) than those on the others. This led to higher FFA selectivities on CHT3 and CHT4 (see Fig. 1). The CHT3 catalyst mainly produced tetrahydrofurfuryl alcohol (THFA), the amount of which decreased rapidly during the operation. Other byproducts on this catalyst were 5-methylfurfuryl alcohol (MFFA) and $\gamma$-valerolactone (GVL). However, CHT3 also produced MFF with a gradual increasing trend. As can be seen in Fig. S1, the main byproduct of the hydrogenation process over CHT4 was THFA as observed in the case of CHT3. Other important byproducts on this catalyst were MF, difurfuryl ether (FFE) and 1-pentanol (1POL). Interestingly, the most active and durable catalyst (CHT4) did not produce MFF, in contrast with the other counterparts. This finding alludes to some detrimental role of MFF in the sustained production of FFA.

The significant effect of pre-calcination of the support, as well as the role of $\mathrm{Cr}$ promoter on the catalytic performance motivated us to study and compare the four catalysts from a structural point of view. For this purpose, all prepared catalysts were characterized by using the SEM, EDX, XRD and elemental mapping techniques and the BET method. Interestingly, the comparison of the BET surface areas of the catalysts (Table 1) revealed that a precalcination of the support remarkably reduces the BET surface area. As shown, the CHT1 and CHT2 samples exhibited very low surface areas (less than $2 \mathrm{~m}^{2} \mathrm{~g}^{-1}$ ) while the uncalcined counterparts had high surface areas (more than $120 \mathrm{~m}^{2} \mathrm{~g}^{-1}$ ). Moreover, the CHT4 sample, which contained $\sim 5 \mathrm{wt} \%$ of $\mathrm{Cr}$ as measured by EDX analysis, showed a considerably higher surface area than CHT3. Noteworthy, the surface 


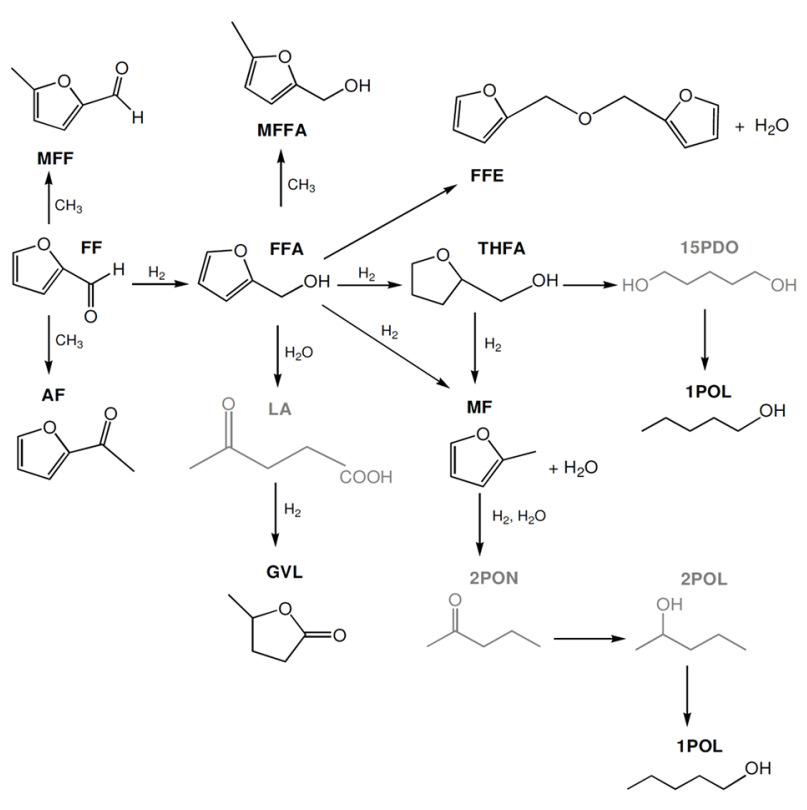

Figure 2. A schematic diagram of the plausible reaction network for the activity of the four synthesized catalysts (the plain compounds are those that were not detected in the effluent stream).

area of the bare calcined hydrotalcite was $100.7 \mathrm{~m}^{2} \mathrm{~g}-$ 1. This observation established that the incorporation of $\mathrm{Cu}$ with or without promoter and the subsequent calcination can dramatically decrease the surface area of the HT. Having these data, we attributed the superior catalytic activity of CHT3 and CHT4 to their higher surface area. This influence might be surprising considering the so-called memory effect (Shylesh et al., 2016; Kanezaki, 1998; Nishimura et al., 2013; Cavani et al., 1991) known for the layered double hydroxides. A reasonable explanation for this complexity would be a partial collapse of the hydrotalcite structure that reduced the internal surface area. Similar studies (Kowalik et al., 2013) reported structural transformations of HT material into crystalline nonlayered oxide phases such that the material lost its capability to recover its layered structure. In fact, hydrotalcites calcined in the temperature range of $350-550{ }^{\circ} \mathrm{C}$ are known to be susceptible to partial/ total destruction by exposure to water (Shylesh et al., 2016; Nishimura et al., 2013; Wang et al., 2012; Zhu et al., 2014) which in turn leads to a loss of surface area (Shylesh et al., 2016; Cavani et al., 1991; Nishimura et al., 2013) followed possibly by the appearance of some broad, ill-defined diffraction peaks attributed to periclase (vide infra) (Shylesh et al., 2016).

To provide more insight into the structural features of the catalysts, SEM/EDX and elemental mapping analyses were also performed (Fig. S2). As depicted in this figure, the morphologies of the catalysts prepared from calcined and uncalcined supports are clearly distinguished. Furthermore, the presence of $\mathrm{Cr}$ as a promoter can induce changes in the morphology. However, the SEM images of CHT1 and CHT2 exhibited some degree of similarity and both catalysts showed aggregated morphologies. Analogous morphological changes have been reported previously (Wang et al., 2016; Zhu et al., 2014). Nevertheless, the introduction of $\mathrm{Cr}$ caused more roughness. In the case of CHT4 the catalytic species are presented in the form of small particulates while in CHT3 large particles are formed and aggregated. The EDX analyses of all samples demonstrate the presence of $\mathrm{Mg}, \mathrm{Al}, \mathrm{O}$, and $\mathrm{Cu}$ atoms. Moreover, the $\mathrm{Cr}$ atom was detectable in the cases of CHT2 and CHT4. The elemental mapping analyses proved that the $\mathrm{Cu}$ species were more abundant in the cases of CHT3 and CHT4. It is worth mentioning that the stacking of $\mathrm{Mg}$ and $\mathrm{Al}$ was more pronounced in CHT3 and CHT4 and their dispersions were uniform. Considering these results, it can be concluded that the uncalcined support had higher stacking and uniformity, which could result in a better immobilization of $\mathrm{Cu}$ species and consequently a superior catalytic activity.

The XRD patterns (Fig. 3) were also used to disclose the effect of pre-calcination of the support on the structural features of the catalysts. As depicted in this figure, the XRD patterns of all catalysts exhibited the characteristic peaks of MgO (JCPDS card No. 450946) and $\mathrm{CuO}$ (JCPDS card No. 89-5898 and 45-0937). Moreover, the intensities of the characteristic peaks for the uncalcined samples were more pronounced. Additionally, no characteristic peaks for $\mathrm{Cr}$ species were detectable on CHT2 and CHT4. According to the

Table 1. Textural properties and EDX chemical compositions of HT and the impregnated catalysts.

\begin{tabular}{lccccc}
\hline \multirow{2}{*}{ Sample } & Surface area $\left(\mathrm{m}^{2} / \mathrm{g}\right)$ & Pore volume $\left(\mathrm{cm}^{3} / \mathrm{g}\right)$ & $\begin{array}{c}\mathrm{CuO} \text { crystallite size } \\
(\mathrm{nm})\end{array}$ & \multicolumn{2}{c}{ Surface loading (wt $\%)$} \\
\cline { 4 - 6 } HT & 100.7 & 0.53 & $3 / 4$ & 0.0 & 0.0 \\
CHT1 & 1.4 & 0.29 & 14.5 & 11.5 & 0.0 \\
CHT2 & 1.5 & 0.14 & 15.7 & 4.9 & 2.2 \\
CHT3 & 126.1 & 1.80 & 12.3 & 9.2 & 0.0 \\
CHT4 & 177.0 & 0.73 & 22.0 & 13.1 & 4.8 \\
\hline
\end{tabular}


previous reports (Mallik et al., 2006), this observation can be ascribed to the high dispersion of promoter on the catalyst. A well-crystallized periclase (MgO) structure was formed along with a tenorite phase in the pre-calcined samples, indicating the partial collapse of the hydrotalcite structure (Shylesh et al., 2016; Comelli et al., 2013). Moreover, the XRD patterns of CHT1 and CHT2 gave no reflection for the presence of additional alumina phases; the diffraction peaks of these catalysts presented slightly higher $2 \theta$ values compared to those of pure periclase, suggesting that the $\mathrm{Al}^{3+}$ cations were incorporated into the $\mathrm{MgO}$ lattice (Shylesh et al., 2016; Kanezaki, 1998).

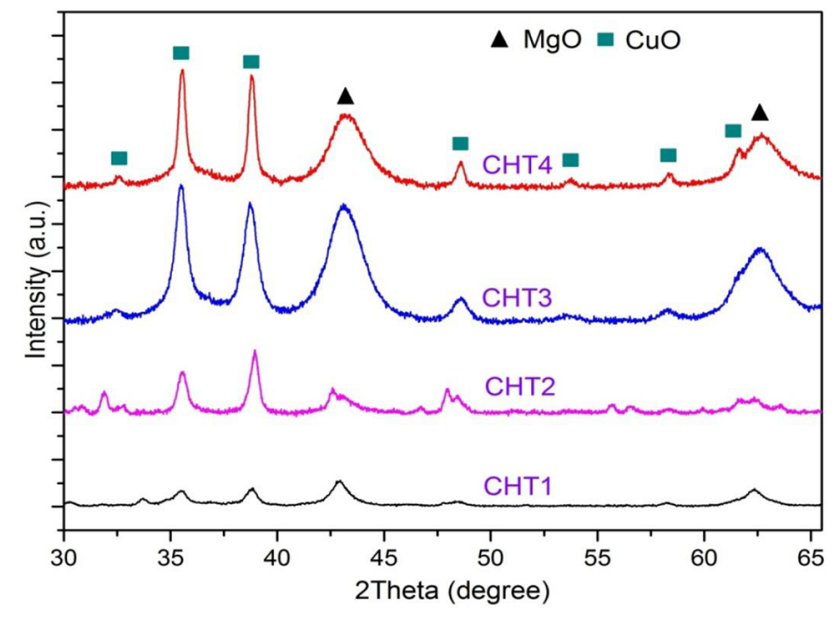

Figure 3. XRD patterns of the four synthesized catalysts.

Using the Scherrer equation, the $\mathrm{CuO}$ crystallite sizes were calculated for all samples (Table 1). As is obvious, this value changed in the order of CHT3 $<$ CHT $1<$ CHT $2<$ CHT 4 indicating that the incorporation of $\mathrm{Cr}$ can result in an increase in the $\mathrm{CuO}$ crystallite size. This effect is more obvious in the case of uncalcined support.

Fig. 4 illustrates the TGA and DTG curves of the spent catalysts within the temperature range of 25-800 ${ }^{\circ} \mathrm{C}$. For all synthesized catalysts, endothermic valleys related to different kinds of carbonaceous deposits were observed in the DTG curves. The weight loss in the range of approximately $200-450{ }^{\circ} \mathrm{C}$ was attributed to the soft coke. However, any other weight losses at higher temperatures could be assigned to the hard coke (Zhang et al., 2014; Ghashghaee et al., 2017). A significant weight loss was associated with CHT1 with two considerable valleys between $300-650{ }^{\circ} \mathrm{C}$ (see Fig. 4), the first valley regarded as soft coke and the second one attributed to hard coke. These observations were consistent with the extremely poor performance of CHT1 in hydroconversion of FF. More
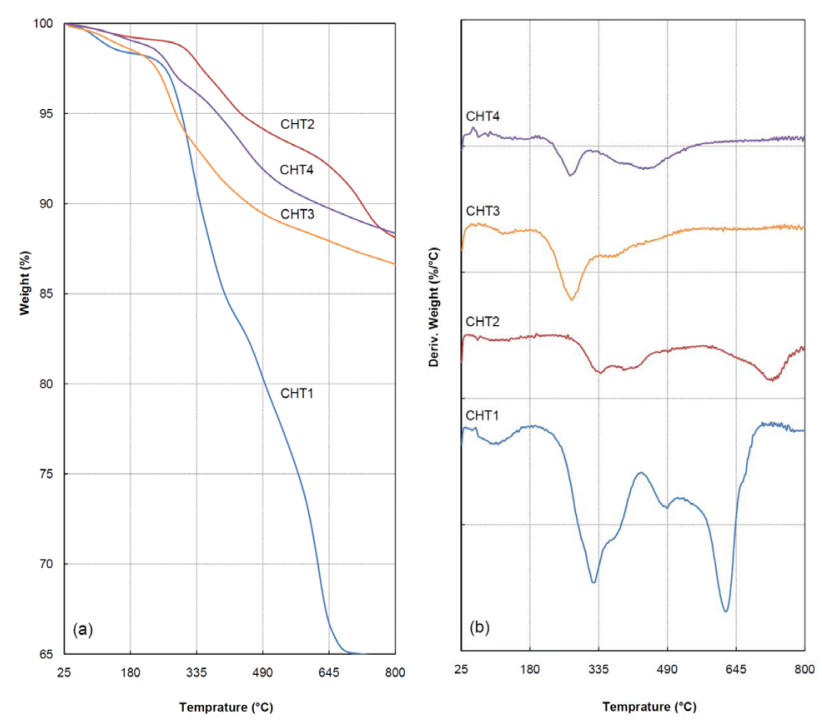

Figure 4. Thermogravimetric (a) and derivative thermogravimetric (b) curves of the spent catalysts.

precisely, the catalyst suffered from deactivation at the beginning of the hydrogenation process (see Fig. 1). The lowest amount of soft coke belonged to CHT4, which displayed the highest catalytic performance in terms of activity, FFA selectivity and durability among others. Among the four fabricated catalysts, the least weight losses were observed for CHT2 and CHT4, which were chromium-promoted catalysts. From this observation, one may conclude that the presence of chromium inhibited the formation of carbonaceous residues (see Fig. 4(a)). Although CHT2 showed the second lowest amount of weight loss during coke burnout, it experienced the deposition of hard coke as associated with $\mathrm{CHT} 1$, but with relatively harder deposits (compare the temperature peaks in Fig. 4(b)). This observation supports the less favorable activity on CHT2 than on CHT4.

\section{CONCLUSION}

For the first time, copper and chromium-doped copper catalysts supported on hydrotalcite were applied to the gas-phase hydrogenation of furfural. In summary, the exertion of a pre-calcination of hydrotalcite support can affect the structural features of the resulting copper catalyst and consequently the catalytic performance. The presence of $\mathrm{Cr}$ promoter can also influence these parameters. In an excellent agreement with the surface area measurements, the $\mathrm{Cu} / \mathrm{HT}$ catalyst with $\mathrm{Cr}$ promoter with no precalcination rendered the most active and stable catalyst towards furfuryl alcohol, with a selectivity of $>94 \%$ and a furfural conversion of $89 \%$. Interestingly, 
no 5-methylfurfurl was produced over this durable catalyst, in contrast with the other counterparts.

\section{ACKNOWLEDGMENT}

The authors appreciate partial support from Iran Polymer and Petrochemical Institute. The assistance of Dr. Mehdi Ghambarian in the thermogravimetric analyses is also gratefully acknowledged.

\section{REFERENCES}

Aldosari O.F., Iqbal S., Miedziak P.J., Brett G.L., Jones D.R., Liu X., Edwards J.K., Morgan D.J., Knight D.K. and Hutchings G.J., Pd-Ru/TiO Catalyst-an Active and Selective Catalyst for Furfural Hydrogenation. Catal. Sci. Technol., 6(1) 234-242 (2016).

An K., Musselwhite N., Kennedy G., Pushkarev V.V., Robert Baker L. and Somorjai G.A., Preparation of mesoporous oxides and their support effects on $\mathrm{Pt}$ nanoparticle catalysts in catalytic hydrogenation of furfural. Journal of Colloid and Interface Science, 392 122-128 (2013).

Basini L., Fornasari G., Trifiro F. and Vaccari A., Material having layered structure of hydrotalcite type, and uses thereof. Patent EP0725038 B1 (2002).

Baskaran T., Christopher J. and Sakthivel A., Progress on layered hydrotalcite (HT) materials as potential support and catalytic materials. RSC Advances, 5(120) 98853-98875 (2015).

Cavani F., Trifirò F. and Vaccari A., Hydrotalcitetype anionic clays: Preparation, properties and applications. Catalysis Today, 11(2) 173-301 (1991).

Comelli N.A., Ruiz M.L., Merino N.A., Lick I.D., Rodríguez-Castellón E., Jiménez-López A. and Ponzi M.I., Preparation and characterisation of calcined $\mathrm{Mg} / \mathrm{Al}$ hydrotalcites impregnated with alkaline nitrate and their activities in the combustion of particulate matter. Applied Clay Science, 80-81, 426-432 (2013).

Cui H., Wu X., Chen Y., Zhang J. and Boughton R.I., Influence of copper doping on chlorine adsorption and antibacterial behavior of $\mathrm{MgO}$ prepared by coprecipitation method. Materials Research Bulletin, 61 511-518 (2015).

D'Oca C.R.M., Naciuk F.F., Silva J.C., Guedes E.P., Moro C.C., D'Oca M.G.M., Santos L.S., Natchigall F.M. and Russowsky D., New Multicomponent Reaction for the Direct Synthesis of $\beta$-Aryl- $\gamma$ - nitroesters Promoted by Hydrotalcite-Derived Mixed Oxides as Heterogeneous Catalyst. Journal of the Brazilian Chemical Society, 28 285-298 (2017).

De Jong W. and Marcotullio G., Overview of Biorefineries based on Co-Production of Furfural, Existing Concepts and Novel Developments. International Journal of Chemical Reactor Engineering, 8(1), A69 (2010).

Eskandari M., Kia A., Afrasiabi S., Dara A., Fahimizadeh M. and Maddah H., Experimental study of biodiesel fuel production from Euphorbiaceae using a $\mathrm{Ca}-\mathrm{Al}-\mathrm{CO}_{3}$ hydrotalcite catalyst. Energy Sources, Part A: Recovery, Utilization, and Environmental Effects, 39(2) 225231 (2017).

Estrup A.J., Selective Hydrogenation of Furfural to Furfuyl Alcohol over Copper Magnesium Oxide. MSc, University of Maine (2015).

Farzaneh V., Shirvani S., Sadjadi S. and Ghashghaee M., Promoting Effects of Calcium on the Performance of Cu-MgO Catalyst in Hydrogenation of Furfuraldehyde. Iran. J. Catal., 7(1) 53-79 (2017).

Ghashghaee M., Sadjadi S., Shirvani S. and Farzaneh V., A Novel Consecutive Approach for the Preparation of $\mathrm{Cu}-\mathrm{MgO}$ Catalysts with High Activity for Hydrogenation of Furfural to Furfuryl Alcohol. Catal. Lett., 147(2) 318-327 (2017).

Halilu A., Ali T.H., Atta A.Y., Sudarsanam P., Bhargava S.K. and Abd Hamid S.B., Highly Selective Hydrogenation of Biomass-Derived Furfural into Furfuryl Alcohol Using a Novel Magnetic Nanoparticles Catalyst. Energy Fuels, 30 2216-2226 (2016).

Hernández W.Y., Aliç F., Verberckmoes A. and Van Der Voort P., Tuning the acidic-basic properties by $\mathrm{Zn}$-substitution in $\mathrm{Mg}$-Al hydrotalcites as optimal catalysts for the aldol condensation reaction. Journal of Materials Science, 52(1) 628-642 (2017).

Jiménez-Gómez C.P., Cecilia J.A., Durán-Martín D., Moreno-Tost R., Santamaría-González J., MéridaRobles J., Mariscal R. and Maireles-Torres P., Gasphase hydrogenation of furfural to furfuryl alcohol over $\mathrm{Cu} / \mathrm{ZnO}$ catalysts. J. Catal., 336 107-115 (2016).

Kanezaki E., Direct Observation of a Metastable Solid Phase of $\mathrm{Mg} / \mathrm{Al} / \mathrm{CO}_{3}$-Layered Double Hydroxide by Means of High Temperature in Situ Powder XRD and DTA/TG. Inorganic Chemistry, 37(10) 2588-2590 (1998). 
Karthikeyan C. and Karuppuchamy S., Transesterification of Madhuca longifolia Derived Oil to Biodiesel Using Mg-Al Hydrotalcite as Heterogeneous Solid Base Catalyst. Materials Focus, 6(2) 101-106 (2017).

Kijeński J., Winiarek P., Paryjczak T., Lewicki A. and Mikołajska A., Platinum deposited on monolayer supports in selective hydrogenation of furfural to furfuryl alcohol. Appl. Catal. A-Gen., 233(1-2), 171-182 (2002).

Kowalik P., Konkol M., Kondracka M., Próchniak W., Bicki R. and Wiercioch P., Memory effect of the CuZnAl-LDH derived catalyst precursor-In situ XRD studies. Appl Catal A-Gen, 464-465, 339 (2013).

Lesiak M., Binczarski M., Karski S., Maniukiewicz W., Rogowski J., Szubiakiewicz E., Berlowska J., Dziugan P. and Witońska I., Hydrogenation of Furfural over $\mathrm{Pd}-\mathrm{Cu} / \mathrm{Al}_{2} \mathrm{O}_{3}$ Catalysts. The Role of Interaction between Palladium and Copper on Determining Catalytic Properties. J. Mol. Catal. A-Chem., 395 337-348 (2014).

Li F., Cao B., Ma R., Liang J., Song H. and Song $\mathrm{H}$., Performance of $\mathrm{Cu} / \mathrm{TiO}_{2}-\mathrm{SiO}_{2}$ catalysts in hydrogenation of furfural to furfuryl alcohol. Can. J. Chem. Eng., 94(7), 1368-1374 (2016a).

Li J., Liu J.-1., Zhou H.-j. and Fu Y., Catalytic Transfer Hydrogenation of Furfural to Furfuryl Alcohol over Nitrogen-Doped Carbon-Supported Iron Catalysts. ChemSusChem, 9(11), 1339-1347 (2016b).

Li M., Hao Y., Cárdenas-Lizana F. and Keane M.A., Selective production of furfuryl alcohol via gas phase hydrogenation of furfural over $\mathrm{Au} / \mathrm{Al}_{2} \mathrm{O}_{3}$. Catal. Commun., 69 119-122 (2015).

Li X., Jia P. and Wang T., Furfural: A Promising Platform Compound for Sustainable Production of $\mathrm{C}_{4}$ and $\mathrm{C}_{5}$ Chemicals. ACS Catal., 7621-7640 (2016c).

Li Y.-j., Yang M., Zhang X.-j., Wu T., Cao N., Wei $\mathrm{N}$. and Wang J., Adsorption removal of thiocyanate from aqueous solution by calcined hydrotalcite. Journal of Environmental Sciences, 18(1) 23-28 (2006).

Liu H., Hu Q., Fan G., Yang L. and Li F., Surface synergistic effect in well-dispersed $\mathrm{Cu} / \mathrm{MgO}$ catalysts for highly efficient vapor-phase hydrogenation of carbonyl compounds. Catal. Sci. Technol., 5(8) 3960-3969 (2015).

Liu K., Xu Y., Yao Z., Miras H.N. and YSong Y.-F., Polyoxometalate-Intercalated Layered Double Hydroxides as Efficient and Recyclable
Bifunctional Catalysts for Cascade Reactions. ChemCatChem, 8 929-937 (2016).

Mallik S., Dash S.S., Parida K.M. and Mohapatra B.K., Synthesis, characterization, and catalytic activity of phosphomolybdic acid supported on hydrous zirconia. Journal of Colloid and Interface Science, 300(1) 237-243 (2006).

Manikandan M., Venugopal A.K., Nagpure A.S., Chilukuri S. and Raja T., Promotional effect of Fe on the performance of supported $\mathrm{Cu}$ catalyst for ambient pressure hydrogenation of furfural. RSC Adv., 6(5), 3888-3898 (2016a).

Manikandan M., Venugopal A.K., Prabu K., Jha R.K. and Thirumalaiswamy R., Role of surface synergistic effect on the performance of $\mathrm{Ni}$ based hydrotalcite catalyst for highly efficient hydrogenation of furfural. J. Mol. Catal. A-Chem., 417, 153-162 (2016b).

Marcotullio G., The Chemistry and Technology of Furfural Production in Modern LignocelluloseFeedstock Biorefineries. PhD, Delft University of Technology (2011).

Marcotullio G., Furfural production in modern lignocellulose-feedstock biorefineries. UNECE/ FAO Workshop. St. Petersburg (2013).

Nagaraja B.M., Kumar V.S., Shasikala V., Padmasri A.H., Sreedhar B., Raju B.D. and Rao K.S., A highly efficient $\mathrm{Cu} / \mathrm{MgO}$ catalyst for vapour phase hydrogenation of furfural to furfuryl alcohol. Catal Commun, 4(6) 287-293 (2003).

Nagaraja B.M., Padmasri A.H., David Raju B. and Rama Rao K.S., Vapor phase selective hydrogenation of furfural to furfuryl alcohol over $\mathrm{Cu}-\mathrm{MgO}$ coprecipitated catalysts. J Mol Catal A, 265(1-2), 90-97 (2007).

Nagaraja B.M., Padmasri A.H., Raju B.D. and Rama Rao K.S., Production of hydrogen through the coupling of dehydrogenation and hydrogenation for the synthesis of cyclohexanone and furfuryl alcohol over different promoters supported on $\mathrm{Cu}$ $\mathrm{MgO}$ catalysts. International Journal of Hydrogen Energy, 36(5) 3417-3425 (2011).

Nakagawa Y., Takada K., Tamura M. and Tomishige K., Total Hydrogenation of Furfural and 5-Hydroxymethylfurfural over Supported Pd-Ir Alloy Catalyst. ACS Catal., 4(8) 2718-2726 (2014).

Nishimura S., Takagaki A. and Ebitani K., Characterization, synthesis and catalysis of hydrotalcite-related materials for highly efficient materials transformations. Green Chemistry, 15(8) 2026-2042 (2013). 
O'Driscoll Á., Curtin T., Hernandez W.Y., Van Der Voort P. and Leahy J.J., Hydrogenation of furfural with a Pt-Sn catalyst: The suitability to sustainable industrial application. Org. Process Res. Dev., 20(11) 1917-1929 (2016).

Sadjadi S., Farzaneh V., Shirvani S. and Ghashghaee M., Preparation of $\mathrm{Cu}-\mathrm{MgO}$ catalysts with different copper precursors and precipitating agents for the vapor-phase hydrogenation of furfural. Korean $\mathrm{J}$. Chem. Eng., 34(3) 692-700 (2017).

Sangeetha P., Nagaraja B.M., Shanthi K. and Narayanan S., Vapour phase hydrogenation of furfural over palladium supported catalyst. Bull. Catal. Soc. India, 8 52-63 (2009).

Santos J.L., Reina T.R., Ivanova S., Centeno M.A. and Odriozola J.A., Gold promoted $\mathrm{Cu} / \mathrm{ZnO} / \mathrm{Al}_{2} \mathrm{O}_{3}$ catalysts prepared from hydrotalcite precursors: Advanced materials for the WGS reaction. Applied Catalysis B: Environmental, 201 310-317 (2017).

Sharma R.V., Das U., Sammynaiken R. and Dalai A.K., Liquid phase chemo-selective catalytic hydrogenation of furfural to furfuryl alcohol. Appl. Catal. A-Gen., 454 127-136 (2013).

Shirvani S., Ghashghaee M., Farzaneh V. and Sadjadi S., Influence of Catalyst Additives on Vapor-Phase Hydrogenation of Furfural to Furfuryl Alcohol on Impregnated Copper/Magnesia. Biomass Conv. Bioref., 8(1) 79-86 (2017).

Shylesh S., Kim D., Gokhale A.A., Canlas C.G., Struppe J.O., Ho C.R., Jadhav D., Yeh A. and Bell A.T., Effects of Composition and Structure of $\mathrm{Mg} /$ Al Oxides on Their Activity and Selectivity for the Condensation of Methyl Ketones. Ind. Eng. Chem. Res., 55(40) 10635-10644 (2016).

Sulmonetti T.P., Pang S.H., Claure M.T., Lee S., Cullen D.A., Agrawal P.K. and Jones C.W., Vapor phase hydrogenation of furfural over nickel mixed metal oxide catalysts derived from layered double hydroxides. Appl. Catal. A-Gen., 517 187-195 (2016).

Taylor M.J., Durndell L.J., Isaacs M.A., Parlett C.M.A., Wilson K., Lee A.F. and Kyriakou G., Highly selective hydrogenation of furfural over supported Pt nanoparticles under mild conditions. Applied Catalysis B: Environmental, 180 580-585 (2016).

Thangaraj B., Jayaraj C., Ganesh V. and Ayyamperumal S., Silicate intercalated cobalt chromiumhydrotalcite (CoCr-HTSi): An environmentfriendly recyclable catalyst for organic transformations. Catalysis Communications, 74 85-90 (2016).

Thirumalaiswamy R., Marimuthu M. and Ashok $\mathrm{K}$.V., Ni containing anionic clay catalyst useful for selective hydrogenation of furfural to furfuryl alcohol and its preparation thereof. Patent WO2015198351 A3 (2015).

Vargas-Hernández D., Rubio-Caballero J.M., Santamaría-González J., Moreno-Tost R., MéridaRobles J.M., Pérez-Cruz M.A., Jiménez-López A., Hernández-Huesca R. and Maireles-Torres P., Furfuryl alcohol from furfural hydrogenation over copper supported on SBA-15 silica catalysts. J. Mol. Catal. A-Chem., 383-384, 106-113 (2014).

Villaverde M.M., Garetto T.F. and Marchi A.J., Liquid-phase transfer hydrogenation of furfural to furfuryl alcohol on $\mathrm{Cu}-\mathrm{Mg}-\mathrm{Al}$ catalysts. Catalysis Communications, 58 6-10 (2015).

Wang J., Xu A., Jia M., Bai S., Cheng X. and Zhaorigetu B., Hydrotalcite-supported Pd-Au nanocatalysts for Ullmann homocoupling reactions at low temperature. New Journal of Chemistry, 41(5) 1905-1908 (2017).

Wang T., Cheng Z., Wang B. and Ma W., The influence of vanadate in calcined $\mathrm{Mg} / \mathrm{Al}$ hydrotalcite synthesis on adsorption of vanadium (V) from aqueous solution. Chemical Engineering Journal, 181 182-188 (2012).

Wang X.D., Iwamoto Y. and Nedachi K., Magnetic Hydrotalcite Composite and Production Method thereof. Patent 20160203893 (2016).

Wei L., Law Z.Z., Qing P., Min Y., Tao C. and Xiaodong L., Hydrotalcite-like structuring catalyst and method for catalytic synthesis of pseudoionone. Patent CN101816950 A (2010).

Xu Y., Qiu S., Long J., Wang C., Chang J., Tan J., Liu Q., Ma L., Wang T. and Zhang Q., In Situ Hydrogenation of Furfural with Additives over a Raney Ni Catalyst. RSC Adv., 5(111) 91190-91195 (2015).

Xu Z.P., Zhang J., Adebajo M.O., Zhang H. and Zhou C., Catalytic applications of layered double hydroxides and derivatives. Applied Clay Science, 53 139-150 (2011).

Yan K. and Chen A., Efficient hydrogenation of biomass-derived furfural and levulinic acid on the facilely synthesized noble-metal-free $\mathrm{Cu}-\mathrm{Cr}$ catalyst. Energy 58 357-363 (2013).

Yan K., Wu X., An X. and Xie X., Novel Preparation of Nano-Composite CuO-Cr2O3 Using CTABTemplate Method and Efficient for Hydrogenation 
of Biomass-Derived Furfural. Functional Materials Letters, 6(01), 1350007 (2013).

Yan K. and Chen A., Selective hydrogenation of furfural and levulinic acid to biofuels on the ecofriendly $\mathrm{Cu}-\mathrm{Fe}$ catalyst. Fuel, 115 101-108 (2014).

Yan K., Wu G., Lafleur T. and Jarvis C., Production, properties and catalytic hydrogenation of furfural to fuel additives and value-added chemicals. Renew. Sust. Energ. Rev., 38 663-676 (2014).

Yuan Q., Zhang D., van Haandel L., Ye F., Xue T., Hensen E.J.M. and Guan Y., Selective liquid phase hydrogenation of furfural to furfuryl alcohol by Ru/Zr-MOFs. J. Mol. Catal. A-Chem., 406 58-64 (2015).

Zhang H., Shao S., Xiao R., Shen D. and Zeng J., Characterization of Coke Deposition in the Catalytic Fast Pyrolysis of Biomass Derivates. Energy \& Fuels, 28(1) 52-57 (2014).

Zhu H., Zhou M., Zeng Z., Xiao G. and Xiao R., Selective hydrogenation of furfural to cyclopentanone over $\mathrm{Cu}-\mathrm{Ni}$-Al hydrotalcite-based catalysts. Korean J. Chem. Eng., 31(4) 593-597 (2014). 